\title{
Proposta de melhoria do processo de Propriedade Intelectual do Instituto Federal de Mato Grosso (IFMT)
}

\author{
Proposal for improvement of the intellectual property process of the Federal Institute of Mato \\ Grosso (IFMT)
}

\author{
Eliel Batista da Silva ${ }^{1}$ \\ Paulo Augusto Ramalho de Souza ${ }^{2}$
}

\section{RESUMO}

Essa ação de extensão e pesquisa foi realizada como produto do Mestrado em Propriedade Intelectual e Transferência de Tecnologia para a Inovação (PROFNIT) e teve como foco o processo de Propriedade Intelectual do Instituto Federal de Mato Grosso (IFMT). Com objetivo voltado para a elaboração de uma proposta de melhoria do processo de gestão de Propriedade Intelectual (PI) do instituto foram realizados diagnósticos em doze Instituições de Ciência e Tecnologia (ICT) brasileiras, entrevistas com técnicos do IFMT e reuniões de sondagens com um especialista em melhoria de processos. O resultado pode tanto contribuir com a gestão e o uso de recursos públicos, bem como servir como possível suporte para melhoria do processo de PI em outras ICT brasileiras.

Palavras-chave: Gestão de Processos. Propriedade Intelectual. Inovação. Melhoria de Processos.

\begin{abstract}
This extension and research action was carried out as the product of the master's degree in Intellectual Property and Technology Transfer for Innovation (PROFNIT), focused on the IP process of the Federal Institute of Mato Grosso (IFMT). With the objective of preparing a proposal to improve the institute's Intellectual Property (IP) management process, diagnoses were carried out in 12 Brazilian Science and Technology Institutions (ICT), appointed with IFMT technicians and survey meetings with a specialist in process improvement. The result can both contribute to the management and use of public resources, as well as to serve as possible support for improving the IP process in other Brazilian ICT.
\end{abstract}

Keywords: Processes management. Intellectual Property. Innovation. Processes Improvement.

\footnotetext{
${ }^{1}$ Mestre em Propriedade Intelectual e Transferência de Tecnologia para a Inovação pela Universidade Federal de Mato Grosso, Brasil; tecnólogo em Gestão Pública no Instituto Federal de Mato Grosso, Brasil (eliel.silva@ifmt.edu.br).

${ }^{2}$ Doutor em Administração pela Universidade Municipal de São Caetano do Sul, São Paulo, Brasil; professor na Universidade Federal de Mato Grosso, Brasil (pauloramalho@ufmt.br).
} 


\section{INTRODUÇÃO}

A disseminação da "cultura da inovação" na comunidade acadêmica no Instituto Federal de Mato Grosso (IFMT) e a recente regulamentação da lei de inovação por meio da Lei $n^{\circ} 13.243 / 2016$ são um desafio para a instituição e para outras ICT brasileiras. Data de 2008 o primeiro registro de Propriedade Intelectual (PI) do IFMT, com um crescimento total de dezesseis registros até o ano de 2019.

A PI caracteriza-se como instrumento legal, de tutela do conhecimento proveniente da criação humana, nos aspectos tecnológicos, artísticos e literários. Além disso, pode estimular o avanço socioeconômico dos países, caso possua uma gestão de PI bem-sucedida, bem como impactar na dinâmica da economia das nações. Portanto, é essencial disseminar informação na gestão de PI e capacitar os recursos humanos para sua utilização, gerando riquezas e trazendo benefícios para a sociedade (SPEZIALI et al., 2019).

A PI compreende um conjunto de direitos que incidem sobre a criação do intelecto humano. Trata-se de um termo genérico utilizado para designar os direitos em relação à propriedade que incide sobre a produção intelectual humana (coisa intangível, ativo intangível), nos domínios industrial, científico, literário e artístico, assegurando ao titular o direito de auferir recompensa pela própria criação, por determinado período de tempo. No Brasil, a PI engloba três grandes áreas: Direito Autoral, Propriedade Industrial e Proteção Sui generis.

No IFMT, verificou-se que, apesar do empenho em estabelecer e promover uma política de inovação, é preciso considerar que essa política ainda não se consolidou, necessitando de planejamento e estratégias para promover uma política mais efetiva que possa ampliar a interação da universidade com a indústria, o governo e outras ICT (PIRES; QUINTELLA, 2015).

Considerando as dificuldades do IFMT em relação à proteção de PI, criou-se em 2010 a Agência de Inovação do IFMT, por meio da Resolução Consup nº 64, de 20 de dezembro de 2010, com o intuito de prospectar, aproximar e desenvolver o tipo mais adequado de aliança estratégica entre os dois atores principais dessa engrenagem tecnológica: comunidade acadêmica com perfil empreendedor e empresas em busca de melhorias nos seus gargalos tecnológicos. Com o avanço do trabalho, conforme números apresentados no Quadro 1, desde o ano de 2011 até o ano de 2019, na Agência da Inovação institucional, percebeu-se a necessidade de uma melhor gestão do processo de proteção da PI, no âmbito dos processos. 
Quadro 1 - Demanda de Propriedade Intelectual na Agência de Inovação do IFMT

\begin{tabular}{|c|c|c|c|c|}
\hline Ano & Patentes & $\begin{array}{c}\text { Programa de } \\
\text { computador }\end{array}$ & Marcas & Total \\
\hline 2011 & -- & 1 & - & 1 \\
\hline 2013 & 1 & -- & - & 3 \\
\hline 2015 & 2 & 1 & - & 2 \\
\hline 2016 & -- & 2 & - & 1 \\
\hline 2017 & 1 & -- & 1 & 1 \\
\hline 2018 & -- & -- & - & 7 \\
\hline 2019 & 4 & 3 & 1 & 16 \\
\hline Total & 8 & 7 & - & - \\
\hline
\end{tabular}

Fonte: Os autores (2021).

Diante do contexto apresentado, o objetivo geral desta ação foi estruturar uma proposta de organização do processo de Gestão de Proteção da PI, em uma Instituição de Ciência e Tecnologia de Mato Grosso, com foco na melhoria do resultado da gestão de PI.

\section{METODOLOGIA}

Para o desenvolvimento da presente ação de extensão com interface na pesquisa, destaca-se que foram relacionadas abordagens junto a todos os envolvidos no processo, frente à necessidade de melhoria do processo de gestão de PI do IFMT.

A etapa inicial contou com a realização de diagnósticos a partir de dados secundários de doze fluxos de processo nos manuais de procedimento de outras ICT brasileiras, com o intuito de consolidar uma estrutura comum de instâncias e passos internos para gestão de processos de PI.

Na segunda etapa foram realizadas três reuniões e entrevistas com técnicos da Agência de Inovação do IFMT, junto à coordenadora da Agência, ao diretor de Pesquisa e ao Pró- 
reitor da PROPES, no ano de 2019, com o intuito de identificar o estado atual do processo de gestão de PI, ou seja, modelar o "As-Is".

A terceira etapa buscou o tratamento dos dados coletados nas reuniões e a comparação com a consolidação dos Manuais de Gestão, no segundo semestre do ano de 2019, de PI identificados em outras ICT brasileiras. Segundo Mello e Salgado (2005), para gerenciar um processo é necessário, primeiramente, visualizá-lo. Assim, o mapeamento foi realizado para representar as diversas tarefas necessárias e a sequência em que elas ocorrem para a realização e entrega de um serviço ou produto. Para tanto, foi realizada uma consolidação do processo de proteção da PI em manuais encontrados nos sites dos Institutos Federais e Universidades e aplicada à ferramenta de Business Process Management (BPM), sendo uma disciplina gerencial que trata processos de negócio como ativos da organização. Pressupõe que os objetivos organizacionais podem ser alcançados por meio da definição, desenho, controle e transformação contínua de processos de negócio; engloba estratégias, objetivos, cultura, estruturas organizacionais, papéis, políticas, métodos e tecnologias para analisar, desenhar, implementar, gerenciar desempenho, transformar e estabelecer a governança de processos (BPM CBOK, 2013). Com foco no diagnóstico e mapeamento do processo de PI institucional, a partir das seguintes etapas: Diagnóstico do processo; Mapeamento; Elaboração de indicadores; Desenvolvimento de artefatos de gestão (BPM CBOK, 2013).

A quarta etapa utilizou reuniões e sondagens com foco na validação das melhorias do processo implementado e na avaliação da linguagem de processos aplicados no modelo proposto.

Destaca-se que a equipe de realização da presente ação de extensão/pesquisa utilizou como suporte para a elaboração dos fluxos de informações dos processos o software Bizagi, em sua versão gratuita para utilização. A ação teve como local de realização de seus trabalhos a Agência de Inovação ${ }^{3}$ localizada na Reitoria do IFMT na cidade de Cuiabá, Mato Grosso.

A Agência de Inovação está institucionalmente vinculada à Pró-Reitoria de Pesquisa, Pós-Graduação e Inovação (PROPES). Como fonte de divulgação, possui o site: inovação.ifmt.edu.br, sendo o órgão responsável por gerir e promover a Política de Inovação adotada pelo Instituto.

\footnotetext{
${ }^{3}$ Inicialmente criada pela Resolução Consup no 64/2010, foi designada com nome de Agência de Inovação Tecnológica. A partir da aprovação da Resolução do Consepe $n^{\circ}$ 05/2020, conforme disposto no Art. $6^{\circ}$, passa a ser denominada apenas Agência de Inovação. 


\section{RESULTADOS E DISCUSSÃO}

O mapeamento de fluxo de processos é uma ferramenta utilizada na melhoria ou transformação de processos que possibilita identificar gargalos, delimitar funções e papéis, prever recursos, estimar custos e mensurar o desempenho do processo, sendo realizada uma análise inicial e atual do estado do fluxo de tarefas para entender se está de acordo com os objetivos propostos, ou seja, quais são os pontos de melhoria do processo.

O mapeamento das atividades permitiu a elaboração de um modelo, ou fluxograma, que represente e explicite, de forma simplificada, a realidade da estrutura das atividades e dos recursos que permitam a organização do processo de PI do IFMT, foco dessa ação de extensão (PAIM et al., 2009), que foi dividido em seis etapas (MEDINA, 2013): $1^{\mathrm{a}}$ Entrevistas com representantes das áreas; $2^{\mathrm{a}}$ - Definição dos processos mais críticos; $3^{\mathrm{a}}$ Modelagem dos processos através de ferramentas que possibilitem o entendimento do trabalho na área; $4^{\mathrm{a}}$ - Proposição de melhorias nas atividades que compõem os processos utilizando o mesmo ferramental; $5^{\mathrm{a}}$ - Análise e modelagem de processos restantes; $6^{\mathrm{a}}$ Discussão dos resultados.

$\mathrm{Na}$ primeira etapa de execução dessa fase foi criada uma planilha utilizando ferramentas de software Excel com o levantamento dos manuais de procedimentos de pedido de depósito ou registro de PI junto ao INPI nos sites dos institutos federais e universidades federais, com o objetivo de criar um banco de dados dos manuais existentes.

Como resultado desse levantamento, localizou-se 12 manuais que influenciaram na elaboração da modelagem do fluxo de procedimentos dos processos de registro de PI da Agência de Inovação do IFMT. Inicialmente, foram identificados, detalhados e mapeados os procedimentos semelhantes de registro de PI, obtidos por meio de análise documental nos manuais de procedimentos que atenderem ao requisito de possuir um fluxo de processo completo para registro de PI junto ao INPI, conforme demonstrado no quadro 2, sendo: Instituto Federal de Sergipe, Instituto Federal Baiano, Instituto Federal de São Paulo, Instituto Federal do Paraná, Instituto Federal do Rio Grande do Sul, Universidade Federal do Rio Grande do Sul, Universidade Federal de Ouro Preto, Universidade de Brasília, Universidade Federal do Rio Grande do Norte, Universidade Federal do Rio de Janeiro, Universidade Federal de Pelotas e Universidade Federal de Mato Grosso. 
Quadro 2 - Mapeamento do fluxo de procedimentos dos processos nos registros de PI junto ao INPI

\begin{tabular}{|c|c|c|c|c|c|}
\hline NIT IF Sergipe & CIT IF Bahia & INOVA IFSP & DIN IFPR & NIT IFRS & DTI UFRG \\
\hline $\begin{array}{c}\text { Consulta sobrea PI } \\
\text { NIT/FS }\end{array}$ & $\begin{array}{l}\text { Comunicar CIT (via } \\
\text { form ul ario Inventor) }\end{array}$ & $\begin{array}{c}\text { Comunicar enviar pelo autor } \\
\text { para INOVA processo de } \\
\text { Registro PI }\end{array}$ & $\begin{array}{c}\text { Divulgação pela D IN } \\
\text { oporturi dades inovaçă } \\
\text { para comuni dade }\end{array}$ & $\begin{array}{l}\text { Encaminhar Formul arios da } \\
\text { solicitação ao Coordenador } \\
\text { NIT, com ciência do Agente }\end{array}$ & $\begin{array}{l}\text { Identificar potencial } \\
\text { inovador do produto }\end{array}$ \\
\hline $\begin{array}{l}\text { Busca anterioridade em } \\
\text { bases de dados }\end{array}$ & Agendar Reunião CIT & $\begin{array}{c}\text { Confèrencia da documentação } \\
\text { pela INOVA }\end{array}$ & $\begin{array}{c}\text { Apoio ao autor na } \\
\text { daboração dos pedido de PI }\end{array}$ & $\begin{array}{c}\text { Coodenador encaminha } \\
\text { formul arios para avaliação } \\
\text { pelo Conselho }\end{array}$ & $\begin{array}{c}\text { Busca previa de } \\
\text { anteri oridade em bases de } \\
\text { dados }\end{array}$ \\
\hline $\begin{array}{l}\text { Apresentação Produto ou } \\
\text { Invenção }\end{array}$ & $\begin{array}{l}\text { Entrega nareunião } \\
\text { formul ario Tecnologia }\end{array}$ & $\begin{array}{c}\text { Analise do quesi to novidade e } \\
\text { val or ação da tecnologia }\end{array}$ & $\begin{array}{l}\text { Acompanhamento na } \\
\text { solicitaçao do regi stro da } \\
\text { proteção }\end{array}$ & $\begin{array}{l}\text { Emissão de decição da } \\
\text { solicitação pelo conselho }\end{array}$ & $\begin{array}{l}\text { Averiguação de } \\
\text { possibilidade registro }\end{array}$ \\
\hline Redação do Texto da PI & Informar parcerias & $\begin{array}{c}\text { Atuação em conjunto autores } \\
\text { e IN OVA na prospecção } \\
\text { transferência da Tecnologia }\end{array}$ & $\begin{array}{l}\text { Pedido registro deve ser } \\
\text { decorrente de projeto } \\
\text { pesquisa cadastrado COPE }\end{array}$ & $\begin{array}{c}\text { Deferido efetua } \\
\text { encaminh amento NIT, } \\
\text { Indeferido devolve ao } \\
\text { solicit ante ou arquivamento }\end{array}$ & $\begin{array}{l}\text { Inexistênci a de } \\
\text { publicação }\end{array}$ \\
\hline Pagamento Taxas GRU & $\begin{array}{c}\text { Realizara busca de } \\
\text { anterioridade }\end{array}$ & $\begin{array}{l}\text { Decição quanto ao interesse } \\
\text { em continuar o processo de } \\
\text { registro }\end{array}$ & $\begin{array}{c}\text { Emissão de parecer } \\
\text { conveniência aceite pedito } \\
\text { de registro PI }\end{array}$ & $\begin{array}{c}\text { NIT solicita ao Solicitante as } \\
\text { demas documentaçóes para } \\
\text { escrita do pedido de proteção } \\
\text { PI }\end{array}$ & $\begin{array}{c}\text { Identificação da natureza } \\
\text { proteção }\end{array}$ \\
\hline $\begin{array}{l}\text { Preenchimento formulario } \\
\text { INPI }\end{array}$ & $\begin{array}{c}\text { Encaminhar pedido Comitê } \\
\text { de araliação }\end{array}$ & $\begin{array}{c}\text { Envio para busca de } \\
\text { anteriori dade por empresa } \\
\text { contratada e elaboração de } \\
\text { relatónio }\end{array}$ & $\begin{array}{l}\text { Preencher formulario de } \\
\text { registro ou deposito via } \\
\text { eletrônica }\end{array}$ & $\begin{array}{c}\text { NIT-IFRS encaminha pedido } \\
\text { ao órgão competente para } \\
\text { registro }\end{array}$ & $\begin{array}{l}\text { Preenchimento de } \\
\text { formularios }\end{array}$ \\
\hline $\begin{array}{c}\text { Encaminhamento registro } \\
\text { INPI }\end{array}$ & $\begin{array}{l}\text { Avaliar possibilidade do } \\
\text { Registro }\end{array}$ & $\begin{array}{c}\text { Envio para redação de patente } \\
\text { por empresa contratada que } \\
\text { elabora a redação }\end{array}$ & $\begin{array}{l}\text { Encaminhamento do } \\
\text { formul ario de registro ou } \\
\text { deposi to para DIN }\end{array}$ & $\begin{array}{l}\text { ONIT e solicitante } \\
\text { acompanha a tramitação e } \\
\text { registor do pedido ate final }\end{array}$ & $\begin{array}{l}\text { Solicitar a abertura de } \\
\text { processo PI no DTI }\end{array}$ \\
\hline \multirow[t]{6}{*}{$\begin{array}{l}\text { Acompanhamento do } \\
\text { processo INPI }\end{array}$} & $\begin{array}{c}\text { Acompanhar aredação } \\
\text { patente }\end{array}$ & $\begin{array}{c}\text { Entrada do processo registro } \\
\text { ou deposito no INPI pela } \\
\text { INOVA }\end{array}$ & $\begin{array}{c}\text { Emissão parecer, solicitar } \\
\text { correções e informações } \\
\text { complementares }\end{array}$ & & $\begin{array}{l}\text { Acompanhar aredação } \\
\text { patente }\end{array}$ \\
\hline & Gerar a GRU & $\begin{array}{c}\text { A companhamento do registro } \\
\text { ou dep osito junto INPI pela } \\
\text { INOVA }\end{array}$ & $\begin{array}{c}\text { Busca previa de } \\
\text { anterioridade em bases de } \\
\text { dados }\end{array}$ & & $\begin{array}{c}\text { Analise formal da } \\
\text { documentação pela DTI }\end{array}$ \\
\hline & $\begin{array}{c}\text { Encaminhar a GRU para } \\
\text { pagament o PROAD }\end{array}$ & & $\begin{array}{c}\text { Elaboração de redação de } \\
\text { patentes por empresa } \\
\text { especializada }\end{array}$ & & $\begin{array}{l}\text { Encaminhar do processo } \\
\text { ao CCTI para deliberação }\end{array}$ \\
\hline & Efetuar registro junto INPI & & $\begin{array}{l}\text { Entrada do registro ou } \\
\text { deposito no INPI }\end{array}$ & & $\begin{array}{c}\text { Emi ssão parecer sobre } \\
\text { interesse institucional na } \\
\text { PI pel a CCTI }\end{array}$ \\
\hline & $\begin{array}{l}\text { Comunicar o Inventor } \\
\text { registro da PI }\end{array}$ & & $\begin{array}{l}\text { A companhamento do } \\
\text { registro ou deposito junto } \\
\text { INPI }\end{array}$ & & $\begin{array}{c}\text { Deposito do pedido da PI } \\
\text { no INPI }\end{array}$ \\
\hline & $\begin{array}{l}\text { Acompanhamento do } \\
\text { processo INPI }\end{array}$ & & & & $\begin{array}{l}\text { Acompanhamento do } \\
\text { pedido, pel a DIT. }\end{array}$ \\
\hline
\end{tabular}


Quadro 2 - Mapeamento do fluxo de procedimentos dos processos nos registros de PI junto ao INPI (continuação)

\begin{tabular}{|c|c|c|c|c|c|}
\hline NTTE UFOP & CDT UNB & NIT UFRN & AI UFRJ & CII UFPel & EIT UFMT \\
\hline $\begin{array}{c}\text { Atendimento Inventor pelo } \\
\text { NITE }\end{array}$ & $\begin{array}{c}\text { Entrevista com Inventores } \\
\text { ou Autores PI }\end{array}$ & $\begin{array}{c}\text { Preencher formulario de } \\
\text { Notific açäo de Invenção e } \\
\text { encaminhar ao NIT pelo } \\
\text { SIGAA }\end{array}$ & $\begin{array}{c}\text { Preenchimento do formulario } \\
\text { de contato na pa gina da } \\
\text { Agência UFRJ }\end{array}$ & $\begin{array}{l}\text { Abrir Processo no SEI de } \\
\text { Registro de PI no CIT }\end{array}$ & $\begin{array}{l}\text { Sol icitar registro e depos to da } \\
\text { PI pelo requer ente }\end{array}$ \\
\hline $\begin{array}{c}\text { Preenchimento } \\
\text { questionário proteção } \mathrm{PI} \\
\text { peloInventor }\end{array}$ & $\begin{array}{l}\text { Preenche um formulärio } \\
\text { invençäo para registrar } \\
\text { abertura do processo no } \\
\text { NUPITEC/CDT }\end{array}$ & $\begin{array}{l}\text { Verificar requisitos de } \\
\text { patenteabilidade, nov ida de e } \\
\text { atividade inventiv a pelo NIT }\end{array}$ & $\begin{array}{c}\text { Formulario enviado equipe } \\
\text { técnica, conhecer o programa } \\
\text { desenvolvido }\end{array}$ & $\begin{array}{l}\text { Preencher Formulàrio de } \\
\text { Informação Tecnológica }\end{array}$ & $\begin{array}{c}\text { Analisar e emitir parecer da PI } \\
\text { pelo EIT }\end{array}$ \\
\hline $\begin{array}{c}\text { Busca estado da técnica e } \\
\text { de anterioridade bases de } \\
\text { dados }\end{array}$ & $\begin{array}{c}\text { Busca prévia de } \\
\text { anterioridade em ba ses de } \\
\text { dados nacionais e } \\
\text { internacionais }\end{array}$ & $\begin{array}{c}\text { Verificação da fase e } \\
\text { parcerias esta belecidas da } \\
\text { pesquisa }\end{array}$ & $\begin{array}{c}\text { Analizar o resultado do } \\
\text { trabalho tem requisitos para } \\
\text { o registro de DI }\end{array}$ & $\begin{array}{c}\text { Preencher Formulario busca } \\
\text { anterioridade bancos de } \\
\text { dados }\end{array}$ & $\begin{array}{l}\text { Elabor ar redaça do registro e } \\
\text { dep osito da PI pelo requer ente } \\
\text { e EIT }\end{array}$ \\
\hline $\begin{array}{l}\text { Re daçäo do documento da } \\
\text { Patente ou Proteçäo }\end{array}$ & $\begin{array}{c}\text { Redaçäo do documento da } \\
\text { Patente }\end{array}$ & $\begin{array}{l}\text { Analice da Notific açäo de } \\
\text { Inv ençäo para a ratificar os } \\
\text { nomes inventores }\end{array}$ & $\begin{array}{c}\text { Pre encher e enviar o } \\
\text { formulario intemo registro } \\
\text { para o Agente de Inovação }\end{array}$ & $\begin{array}{l}\text { Encaminhar processo SDAP } \\
\text { ana lise estado da técnica }\end{array}$ & $\begin{array}{c}\text { Analisar documentaçäo da PI } \\
\text { pelo EIT }\end{array}$ \\
\hline $\begin{array}{c}\text { Pagamentos de taxas GRU } \\
\text { pelo NTTE }\end{array}$ & $\begin{array}{c}\text { Pagamentos de taxas GRU } \\
\text { pelo NUPITEC/CDT }\end{array}$ & $\begin{array}{c}\text { Busca prévia de } \\
\text { anterioridade em bases de } \\
\text { dados INPI e outras }\end{array}$ & $\begin{array}{l}\text { Agência envia para autores } \\
\text { Termo de Cessão para } \\
\text { as sinar e devolver }\end{array}$ & $\begin{array}{l}\text { Entrega da Documentação } \\
\text { Técnica do pedido PI }\end{array}$ & $\begin{array}{l}\text { Busca estado da técnica e de } \\
\text { anteriorida de bases de dados } \\
\text { EIT }\end{array}$ \\
\hline $\begin{array}{c}\text { Depósito do pedido da PI } \\
\text { no INPI }\end{array}$ & $\begin{array}{l}\text { Encaminhamento pedido de } \\
\text { dep ósito ou registro junto } \\
\text { INPI pelo NUPITECiCDT }\end{array}$ & $\begin{array}{c}\text { Verificar a pertinência do } \\
\text { depósito ou registro de PI } \\
\text { pelo NIT }\end{array}$ & $\begin{array}{l}\text { Busca prév ia de } \\
\text { anterioridade em bas es de } \\
\text { dados INPI e outras }\end{array}$ & $\begin{array}{c}\text { Anàlise Prel iminar para } \\
\text { verificar aspectos formais } \mathrm{PI}\end{array}$ & $\begin{array}{c}\text { Solicitar pagamentos de taxas } \\
\text { GRU pelo EIT }\end{array}$ \\
\hline $\begin{array}{l}\text { Acompanhamento do } \\
\text { pedido, pela NITE. }\end{array}$ & $\begin{array}{c}\text { Acompanhamento do } \\
\text { pedido nos tràmites do INPI } \\
\text { pelo NUPITEC/CDT }\end{array}$ & $\begin{array}{c}\text { Encaminhar pedido de } \\
\text { depósito ou registro PI junto } \\
\text { INPI pelo NIT }\end{array}$ & $\begin{array}{c}\text { Encaminhar pedido de } \\
\text { depósito ou registro } \mathrm{PI} \text { junto } \\
\text { INPI pela } \mathrm{Agên} \text { cia }\end{array}$ & $\begin{array}{l}\text { Encaminhar processo para } \\
\text { Análise de Tecnologia } \\
\text { Comitê Institucional de PI }\end{array}$ & $\begin{array}{c}\text { Verificar disponibilidade } \\
\text { financeira e efetuar } \\
\text { pagamento GRU pela } \\
\text { PROAD }\end{array}$ \\
\hline \multirow[t]{3}{*}{$\begin{array}{l}\text { Cumprimento de } \\
\text { exigências do INPI pelo } \\
\text { Inventor/NITE }\end{array}$} & $\begin{array}{c}\text { Efetıar analise para } \\
\text { transferência de tecn ologia } \\
\text { NUPITEC/CDT }\end{array}$ & $\begin{array}{c}\text { Realizar acomp anhamento } \\
\text { pedido de depósito ou } \\
\text { registro PI junto INPI pelo } \\
\text { NIT } \\
\end{array}$ & $\begin{array}{l}\text { A Agência acompanhara } \\
\text { todo oprocesso de registro } \\
\text { PI junto INPI }\end{array}$ & $\begin{array}{l}\text { Protoc olar de Pedido de } \\
\text { depós to no INPI pelo CIT }\end{array}$ & $\begin{array}{l}\text { Depositar opedido registro ou } \\
\text { depósito da PI no INPI }\end{array}$ \\
\hline & & & $\begin{array}{c}\text { Agente resp onsaivel pelo } \\
\begin{array}{c}\text { Registro de PI informara } \\
\text { todo o acompanhamento aos } \\
\text { autores. }\end{array} \\
\end{array}$ & $\begin{array}{l}\text { Acompanhamento do } \\
\text { pedido, pela CIT }\end{array}$ & $\begin{array}{l}\text { Realizar exame formal do } \\
\text { ped ido registro ou depós to da } \\
\text { PI pelo INPI }\end{array}$ \\
\hline & & & & & $\begin{array}{l}\text { Acompanhamento do pedido } \\
\text { ped ido registro ou depósito da } \\
\text { PI pelo EIT }\end{array}$ \\
\hline
\end{tabular}

Fonte: Os autores (2021).

$\mathrm{Na}$ sequência, realizou-se a análise dos procedimentos dos fluxos dos processos, verificando quais procedimentos são comuns e quais procedimentos não possuem relação ou repetição entre eles. Essa análise foi requisito primordial na elaboração da modelagem do fluxo de processo de registro de PI da Agência de Inovação junto ao INPI.

Após a análise do mapeamento dos fluxos dos processos, realizou-se a modelagem do fluxo do processo do pedido de depósito de patente. A modelagem de processos de negócios teve como objetivo tornar os processos mais eficientes e mais eficazes.

Existem algumas ferramentas de suporte para a execução da modelagem de processos empregando o BPM e a notação BPMN. Nessa ação de extensão foi utilizado o software 
Bizagi Modeler, ferramenta que permite modelar os ciclos do processo utilizando anotação. $\mathrm{O}$ uso de uma ferramenta de modelagem, entre outros recursos, possibilita a construção de diagramas, a análise de como o processo se comporta e a documentação desse processo. $\mathrm{O}$ Bizagi Modeler permitiu a simulação dos fluxos de trabalhos a fim de facilitar a análise de melhorias tanto em relação ao tempo quanto em relação ao custo das atividades desenvolvidas, além de ser de fácil utilização. O objetivo principal com a elaboração na modelagem do fluxo de processo de PI da Agência de Inovação/IFMT foi facilitar e simplificar a compreensão para os usuários.

Na elaboração da modelagem do fluxo de procedimentos dos processos de registro de PI da Agência de Inovação/IFMT, foram identificados, detalhados e mapeados os procedimentos de registro de PI do IFMT e, posteriormente, foram comparados com os doze manuais das ICT citadas acima. Após a modelagem, o fluxo de processo de depósito de patente, depois de estar pré-formatado, foi apresentado através de sondagem de opinião a um especialista com doutorado em Administração, que atua em projetos relacionados à melhoria de processos em empresas públicas e privadas há mais de cinco anos.

Foram realizadas duas reuniões de trabalho no formato de entrevistas não estruturadas com o intuito de validar o desenho do processo realizado por meio da análise documental dos manuais identificados em outras IFs e pela sondagem informal no local da Agência de Inovação do IFMT. Na primeira reunião, foi apresentado ao especialista o fluxo do processo de gestão de PI a partir da lógica da Agência de Inovação do IFMT. Após a apresentação, o especialista fez um conjunto de ponderações sobre o uso da linguagem BPMN, com o intuito de otimizar o processo modelado. Na segunda reunião, o especialista realizou apontamentos de falhas, correções e contribuições para a melhoria da modelagem no fluxo do processo. As contribuições do especialista foram relevantes para a reestruturação do processo modelado e validação do diagrama fluxo do processo de registro de PI do IFMT.

No mapeamento do processo, identificaram-se muitas semelhanças entre os diferentes tipos de registros (marcas, programas de computador, desenho industrial e patente). Por isso, optou-se pela elaboração de diagrama do fluxo do processo para pedido de depósito de patente. Para tal, a Figura 1 apresenta o processo modelado do registro de PI do IFMT, o qual serviu de base para a elaboração do manual de procedimentos de Registro de PI para a Agência de Inovação do IFMT. 
Figura 1 - Diagrama de fluxo de processos do pedido de depósito de patente na Agência de Inovação/IFMT no INPI

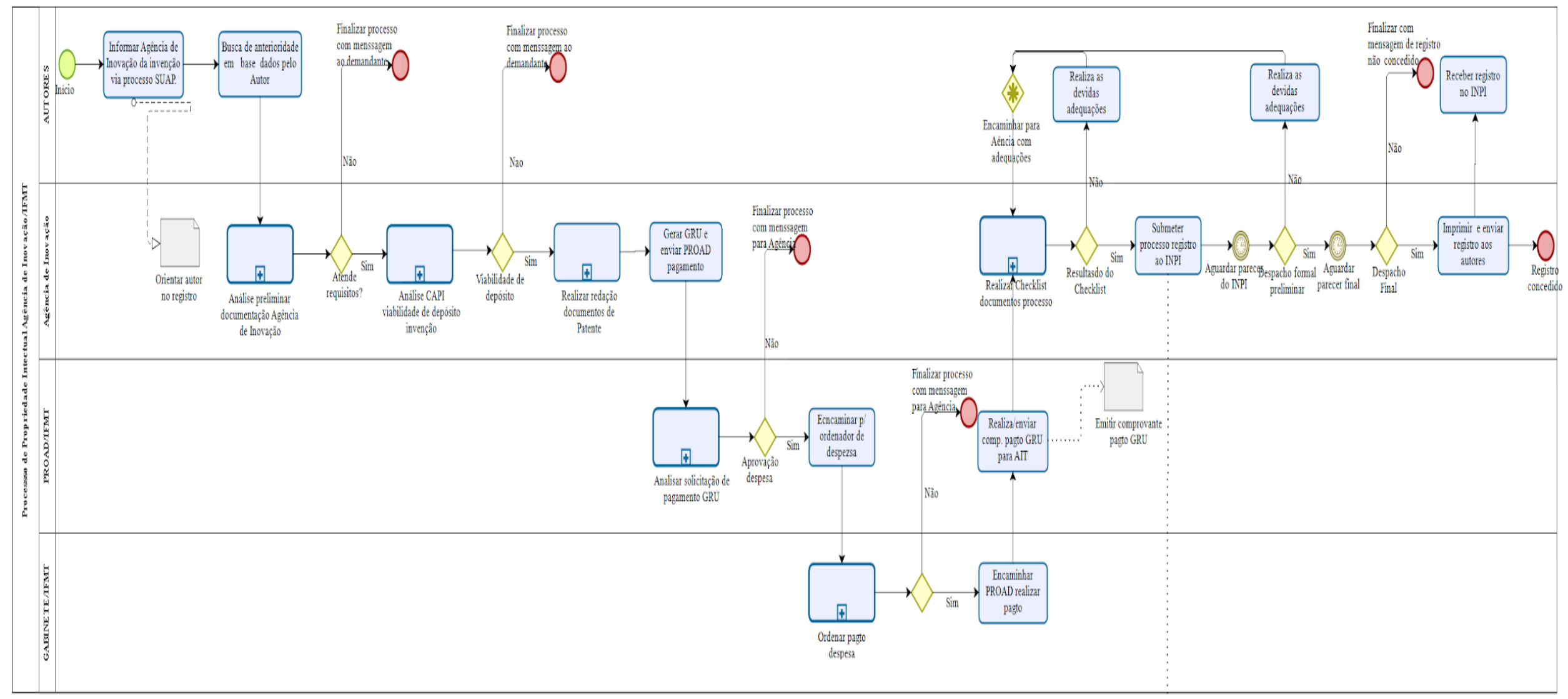

Fonte: Os autores (2021). 
Os diagramas de modelagem do BPMN, com o software Bizagi Modeler, possuem alguns componentes básicos que descrevem o fluxo do processo por meio de representações gráficas, tais como caixas, losangos e setas indicando direções.

Conforme mostrado na Figura 1, o processo de registro de PI perpassa quatro setores do IFMT: tem início com autores informando oficialmente via SUAP quanto à criação ou invenção para a Agência de Inovação. Quando o processo passa pela análise quanto à regularidade dos documentos e viabilidade do registro, tramita pela PROAD e pelo Gabinete da reitoria para providência em relação ao empenho e pagamento das taxas do INPI. A partir desse momento, o processo possui comunicação e depende de algumas instâncias externas, como o INPI. Não será o foco deste trabalho o fluxo de processo de registro de PI no INPI, por analisar que esse fluxo do processo se encontra completamente consolidado.

Destaca-se que, mesmo a ação tendo o foco no mapeamento do fluxo detalhado de Registro de Patentes, foram delineados os fluxos simples do Registro de Marca, Registro de Programa de Computador e Registro de Desenho Industrial, sendo todos eles realizados pela Agência de Inovação do IFMT. Para tal, os fluxos resumidos são apresentados na Figura 2 Registro de Marca; Figura 3 - Programa de Computador; e Figura 4 - Desenho Industrial.

Figura 2 - Resumo dos passos do fluxograma do processo de registro de marca

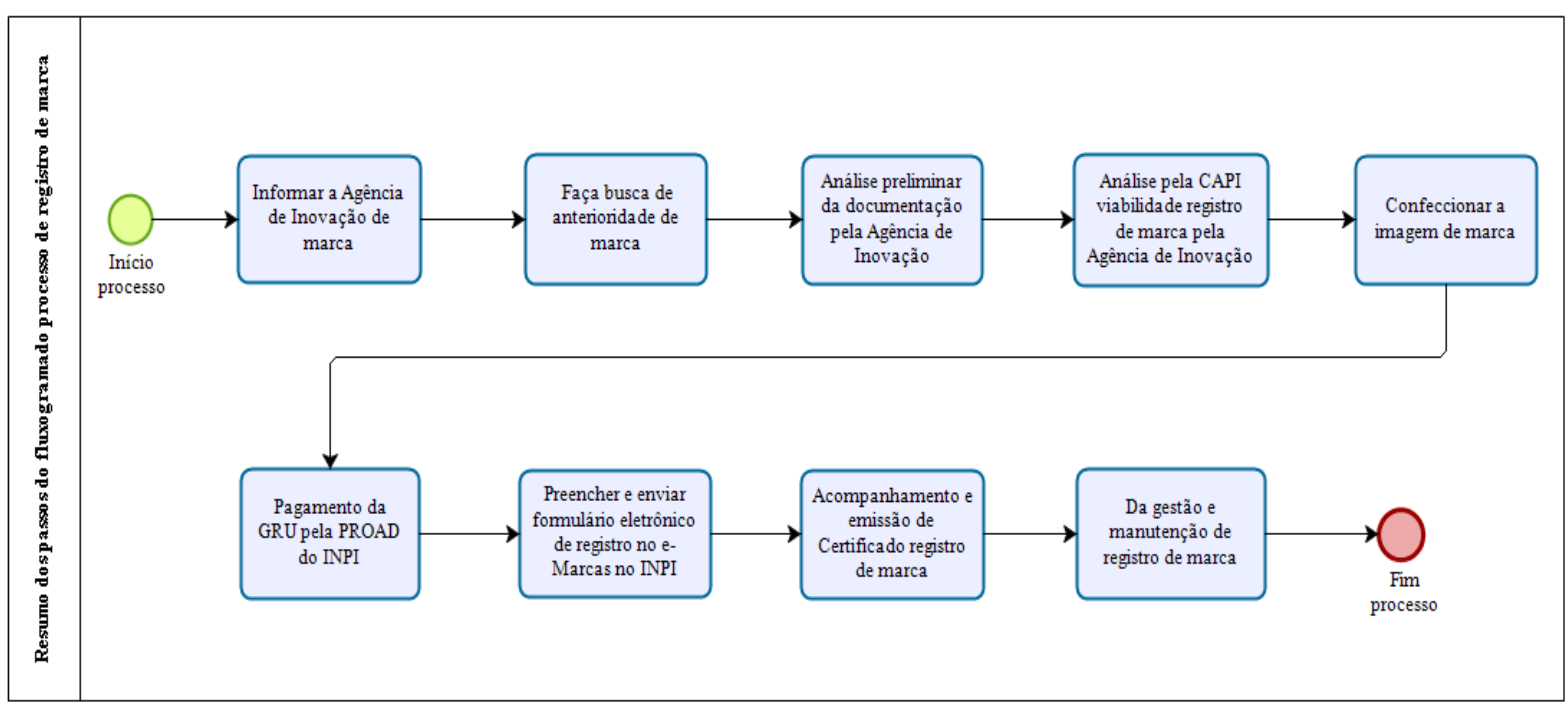

Fonte: Os autores (2021). 
Figura 3 - Resumo do fluxograma do processo no passo a passo de registro de programa de computador

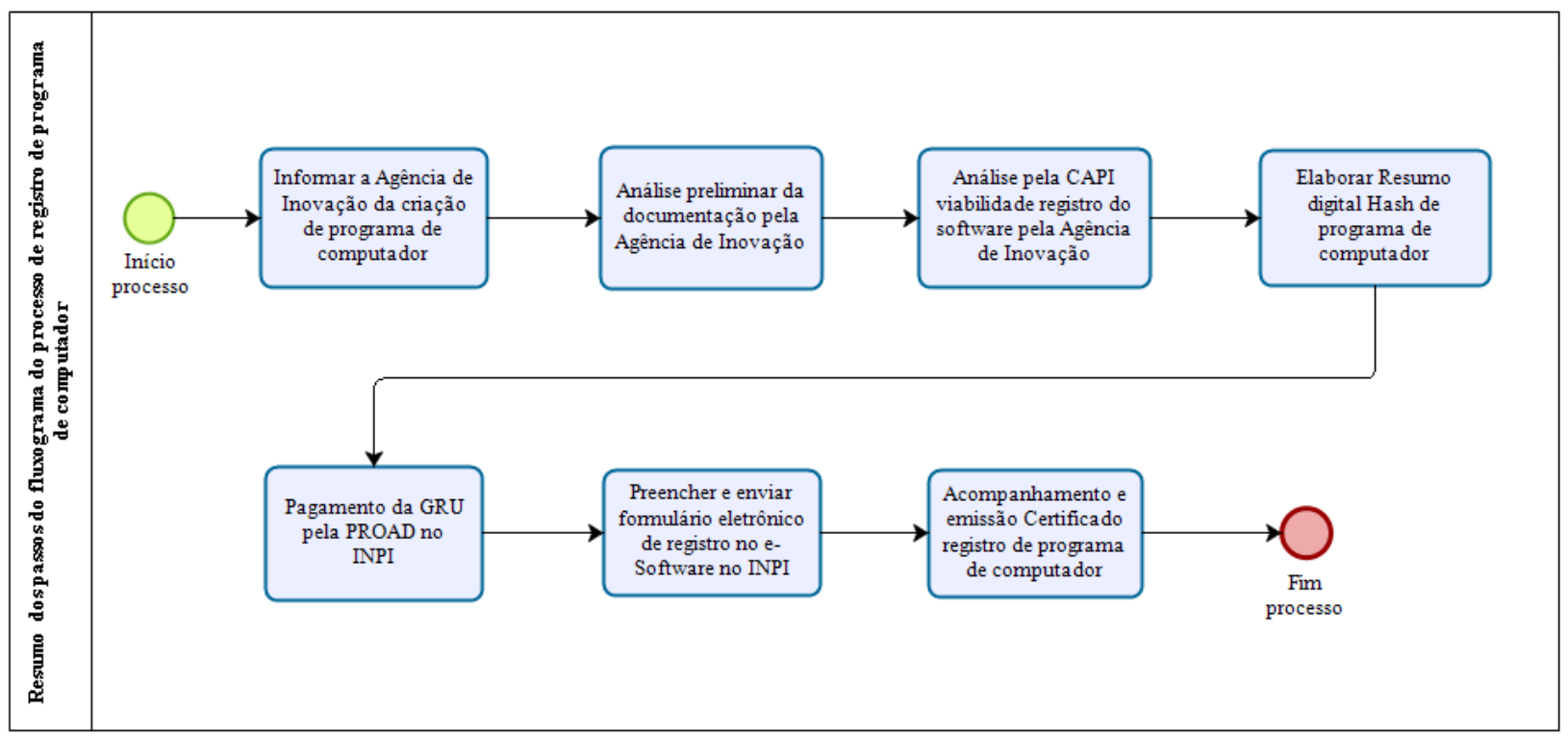

Fonte: Os autores (2021).

Figura 4 - Resumo dos passos do fluxograma de processo no registro de desenho industrial

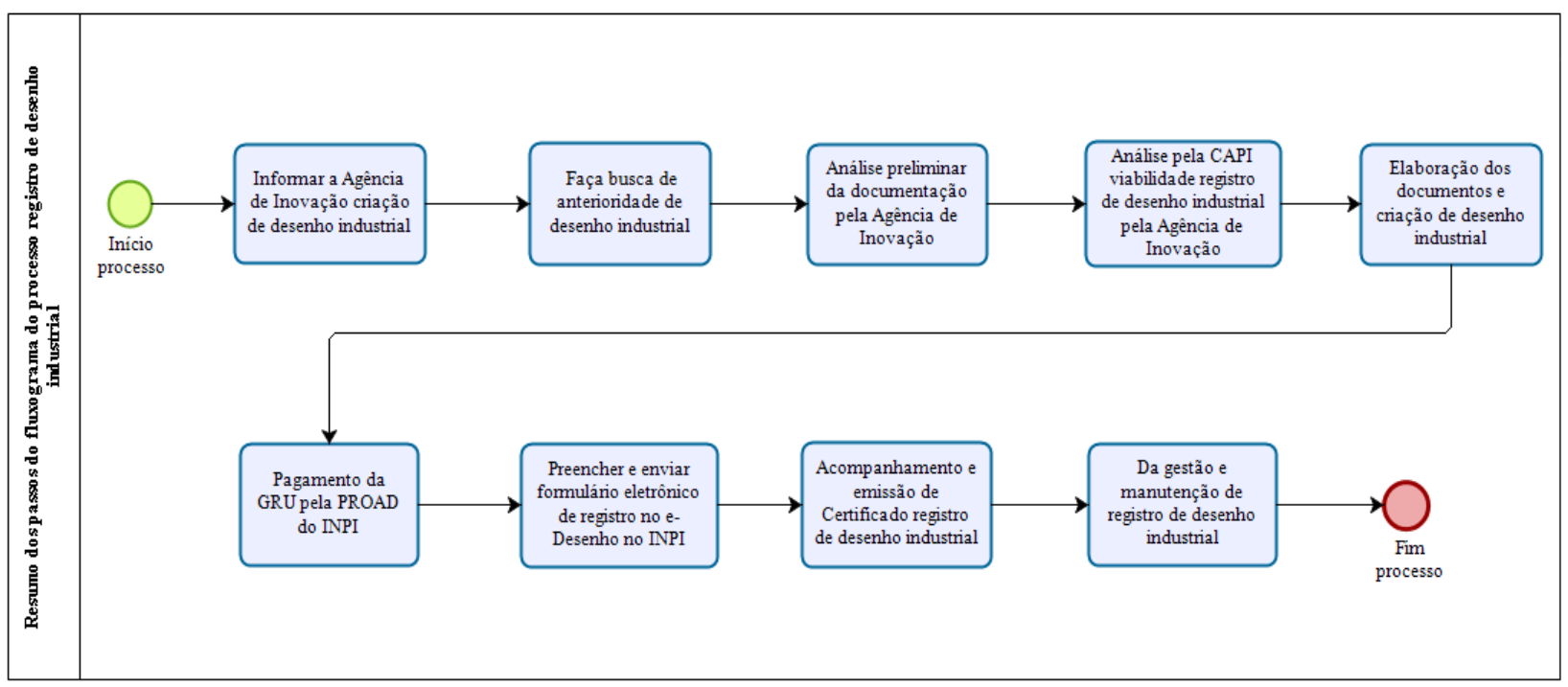

Fonte: Os autores (2021).

O mapeamento e a melhoria do fluxo de processo por meio da presente ação de extensão/pesquisa possibilitaram a elaboração de uma proposta de Manual de Procedimentos, tendo como base o diagrama de modelagem do fluxo do processo de pedido de depósito de patente. Uma cópia no formato digital do manual está disponível na pasta compartilhada da 
PROPES e no site da Agência de Inovação, e cópias no formato impresso, nas bibliotecas dos campi do IFMT.

\section{CONSIDERAÇÕES FINAIS}

A presente ação de extensão possibilitou a melhoria da gestão do processo de PI, possibilitando uma maior eficiência da relação do IFMT com o ambiente externo, ou seja, com o ecossistema de inovação e contribuindo com a conscientização de sua comunidade local sobre a importância da proteção de suas criações e inventos.

A melhoria do processo possibilitou a elaboração do Manual de Procedimento, que se propõe a ser prático e de fácil compreensão, com as referências totalmente disponíveis e acessíveis, visando contribuir com os trabalhos diários de pesquisadores com docentes e técnicos administrativos, facilitando de forma prática a gestão de processo de registro de PI junto ao INPI, à medida que leva melhorias ao local de trabalho com o fornecimento de um documento que deixa bem definidos os procedimentos a serem executados, que seja de fácil acesso e que esteja didaticamente bem redigido em relação ao registro de PI no IFMT.

Por meio da pesquisa, pode-se consolidar um caminho metodológico que pode ser aplicado em outras Instituições de Ciência e Tecnologia, por apresentar uma visão lógica e estruturada de todos os processos envolvidos na elaboração do manual de procedimentos da Agência Inovação, desde a sua concepção até a sua conclusão.

Por fim, espera-se que tanto o processo melhorado quanto o Manual de Procedimentos, elaborados por meio dessa ação, possam contribuir com a Agência de Inovação em gerir e promover a PI institucional do IFMT, pois ações melhoram o fluxo, a comunicação e o avanço da cultura de Propriedade Intelectual no âmbito da Agência de Inovação/IFMT.

\section{REFERÊNCIAS}

ABPMP. BPM CBOK: Guia para o Gerenciamento de Negócio Corpo Comum de Conhecimento ABPMP BPM CBOK V3.0. Brasil: ABPMP, 2013. Disponível em: http://ep.ifsp.edu.br/images/conteudo/documentos/biblioteca/ABPMP_CBOK_Guide_Portu guese.pdf. Acesso em: 5 dez. 2019.

BRASIL. Lei $\mathrm{n}^{\circ} 13.243$, de 11 de janeiro de 2016. Dispõe sobre estímulos ao desenvolvimento científico, à pesquisa, à capacitação científica e tecnológica e à inovação 
[...]. Diário Oficial da União, Brasília, 2016. Disponível em:

https://legislacao.presidencia.gov.br/atos/?tipo=LEI\&numero $=13243 \& a n o=2016 \&$ ato $=\mathrm{dd} 2 \mathrm{Az}$ Yq50dZpWTdc1. Acesso em: 5 dez. 2019.

MEDINA, F. A importância da análise de processos para uma organização. 3. ed. Rio de Janeiro: Bloch, 2013.

MELLO, C. H. P.; SALGADO, E. G. Mapeamento dos processos em serviços: estudo de caso em duas pequenas empresas da área de saúde. In: ENCONTRO NACIONAL DE ENGENHARIA DE PRODUÇÃO, 25., Porto Alegre, 2005. Disponível em: http://www.abepro.org.br/biblioteca/ENEGEP2005_Enegep0207_0556.pdf. Acesso em: 5 dez. 2019.

PAIM, R. et al. Gestão de processos: pensar, agir e aprender. 3. ed. Porto Alegre: Bookman, 2009.

PIRES, E. A.; QUINTELLA, C. M. A. L. T. Política de propriedade intelectual e transferência de tecnologia nas universidades: uma perspectiva do NIT da Universidade Federal do Recôncavo da Bahia. Holos, Natal, v. 6, p. 178-195, 2015. Doi:

10.15628/holos.2015.3600. Disponível em:

https://www2.ifrn.edu.br/ojs/index.php/HOLOS/article/view/3600. Acesso em:

SPEZIALI, M. G. et al. Cartilha de Propriedade Intelectual. Ouro Preto: COGITE, 2016. Disponível em: http://saci2.ufop.br/data/solicitacao/08749_cartilha_nite_versao_final.pdf. Acesso em: 5 dez. 2019.

Submetido em 8 de março de 2021. Aprovado em 17 de junho de 2021. 